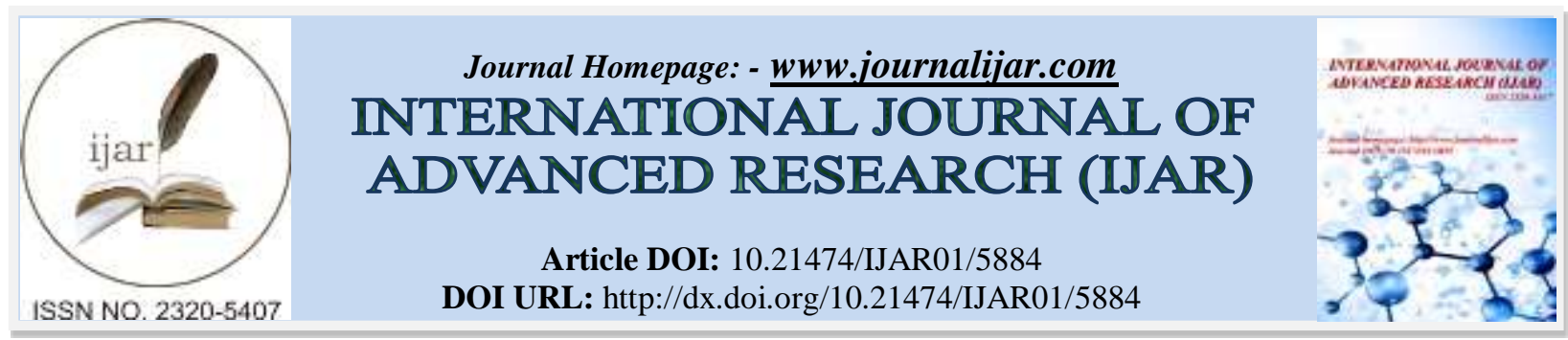

RESEARCH ARTICLE

\title{
A COMPARATIVE STUDY OF TOPICAL TCAA 30\% VERSUS SURGICAL REMOVAL IN TREATMENT OF MOLLUSCUM CONTAGIOSUM IN CHILDREN.
}

Nabeel K. AL_hamzawi and Shedden AL_shammari.

Department of Dermatology, Diwaniya Teaching Hospital, Diwaniya, Iraq.

\section{Manuscript Info}

\section{Manuscript History}

Received: 16 September 2017

Final Accepted: 18 October 2017

Published: November 2017

Key words:-

Topical TCAA 30\%, Molluscum contagiosum, Surgical removal, Comparative study.

\section{Abstract}

Background:- Molluscum contagiosum is a common skin disorder mainly infecting children, and a pox virus causes it. This study was prepared to compare the efficacy, safety, cure rate, and recurrence of topical treatment versus surgical removal of MC.

Methods:- A total of 84 patients included in this study, and divided to receive treatment with either topical trichloroacetic acid $30 \% \operatorname{group}(\mathrm{A})$ for seven days or surgical removal group (B) for one session, until clinical cure observed, the total time of treatment four weeks. Each group included 42 patients. A one year follow up after clinical cure with regular visits every two months to assess the efficacy of treatment, adverse reactions, and recurrence.

Results:- In patients with topical treatment group (A), the cure rate was $88 . \mathrm{I} \%$ (37 of 42) after two weeks of treatment, the other $11.9 \%$ (5 of 42) healed by the end of 4 weeks. Whereas in the group (B) $57.1 \%$ (24of 42) cleared after two weeks, and the remaining 18 (42.8\%) were affected by secondary infection and they cleared by the end of $4^{\text {th }}$ week. However, in the group (A), five patients $11.9 \%$ experienced recurrences of molluscum contagiosum after four months. While in group (B) patients, recurrence of lesions reported in $54.7 \%$ (23of 42) who underwent frequent surgical removal through multiple visits during one year.

Conclusion:- Topical treatment of molluscum contagiosum has more efficacy, safety, and low cost than surgical removal. The recurrence rate is significantly less with topical treatment than with surgical removal.

Copy Right, IJAR, 2017,. All rights reserved.

\section{Introduction:-}

Molluscum contagiosum (MC) is a benign viral infection that mainly affects children. MC virus is a large, brickshaped replicates within the cytoplasm of cells. (1)

The incubation period of MC averages 2-3 months, with a range of 1 week to 6 months. Lesions begin as tiny papules which grow over several weeks to a diameter of $3-5 \mathrm{~mm}$, occasionally enlarging to $10-15 \mathrm{~mm}$, producing the "giant molluscum. Papules are smooth firm, and dome-shaped, with highly characteristic central umbilication. Children more typically develop lesions on the face, trunk, and upper extremities and often with linear distribution 
suggesting autoinoculation by scratching. 10-50\% of infected children have lesions in the genital region. The average duration of untreated disease is reported to be two years, recurrence after clearance occurs in 15-35\% of patients. (2) Treatment of MC generally simple and accomplished by eradicating lesions with mechanical destruction or techniques to induce local epidermal inflammation. While therapy hastens resolution of lesions and may thereby reduce cosmetic concern, autoinoculation, and transmission to others, the high frequency of recurrences and self -limiting nature of the infection must be weighed against the pain and potential for scarring induced by destructive therapies, especially in children. The recommended treatments are involving physical destruction of lesions ( e.g., excisional curettage, cryotherapy, electrosurgery ) or topical application of cytotoxic agents ( e.g., cantharidin, trichloroacetic acid, podophyllin ). (2)(3)

\section{Methods:-}

In this prospective clinical study, 84 patients with molluscum contagiosum consulted the department of dermatology in Diwaniyah teaching hospital, Diwaniyah, Iraq, were enrolled. The study was performed over a period of 13 months from January 2016 to January 2017. The treatment was lasting for four weeks and follow up for twelve months. Inclusion criteria; children below age of twelve years, clinically healthy, having numerous MC included. Exclusion criteria; patients with a single lesion, immunocompromised children, and those with secondary pyogenic infection were excluded from the study. The patients divided into two groups, and each group was selected for either topical TCAA $30 \%$ or surgical removal depending on the number of lesions owned by each patient, and the site where the lesions present. Patients with $<5$ lesions selected for surgical removal whereas those with $>5$ lesions chosen for topical application TCAA 30\%. Lesions located in periorbital, perioral areas, eyelids and lips selected for surgical removal while those located elsewhere treated by topical application. No genital lesions reported in this study. Surgical removal was done by a curette and the area behind irrigated by povidone iodine. The lesions treated by a single session with a maximum treatment period 1-4 weeks. In the TCAA group (A) patients were informed how to apply the TCAA $30 \%$ with the rough end of a toothpick and instructed to use the chemical daily until significant inflammation observed. The total period of treatment was 1-4 weeks.

In both groups follow up visits every week until all lesions cleared, for a maximum of four weeks. Any local effects like redness, swelling, infection, superficial scars recorded during this period. Then, patients in both groups followed for one year after complete clearance for the appearance of new lesions. New lesions treated and included in this study. All data were collected and analyzed using chi- square with a significant statistical results.

\section{Results:-}

A total number of 84 patients with MC, aged 2-12 years (average 5.7) listed in this study. The number of the lesions ranged from 1- 20 (average 8.5). The sites of the lesions included the face, neck, upper extremities, scalp, eyelids, and lips. Lesions on the eyelids treated by surgical removal. The size of the lesions ranged between $1-10 \mathrm{~mm}$ with average $(2.8 \mathrm{~mm})$, giant MC recorded in 6 patients of surgical removal group. The TCAA group included 42 patients aged 4-12 years (mean 6). The number of lesions ranged from 5-20 (mean 10.5), and the size of the lesions ranged from 1-5 mm (mean 2.9). The lesions situated on the forehead, cheeks, scalp and upper trunk. 37 out of 42 have been fully cured after two weeks (mean 1. 6 weeks) and five patients cured by four weeks because they experienced perilesional dermatitis at the site of treatment. Local swelling reported in $16 \%$, redness in $65 \%$ of patients, stinging sensation reported in (54\%), temporary pigmentary changes in $38 \%$ and no scarring was noticed with this modality of treatment. New lesions reported in 5 patients after four months of follow up and each patient presented with 1-3 lesions that treated with the same treatment. The surgical group included 42 patients aged 2-10 years (mean 6.2). The number of lesions from 1-4 (mean 3.3) and the size of the lesions ranged from 3-10mm (mean 4.5). Giant MC reported in 6 patients. The lesions located on the cheeks, periorbital and perioral areas, lesions on the lower eyelid reported in three patients. All patients experienced pain during surgical removal. Local swelling developed in $13(33.3 \%)$ throughout 24 hours after treatment. Secondary pyogenic infection occurred in $26.1 \%$ (11 of 42 ), three days after removal of MC and treated by antibiotics. Superficial scarring and pigmentary changes noticed in $6(14 \%)$ and $11(26 \%)$ respectively. Complete clearance was achieved in $24(57.1 \%)$ by two weeks while $18(42.8 \%)$ cleared by the end of $4^{\text {th }}$ week. New lesions reported in $23(54.7 \%)$, at $2^{\text {nd }}$ and $4^{\text {th }}$ and 6 th month of follow up and treated by surgical removal.

Table- 1:- Comparison between local TCAA 30\% and surgical removal of MC concerning cure rate, adverse reactions, and recurrence.

\begin{tabular}{|l|l|l|l|}
\hline Type of treatment & Cure rate after two weeks & Adverse reactions & Recurrence rate \\
\hline
\end{tabular}




\begin{tabular}{|c|c|c|c|}
\hline $\begin{array}{l}\text { Group A TCAA } 30 \% \\
\mathrm{n}=42\end{array}$ & $37(88.1 \%)$ & $\begin{array}{lr}\begin{array}{l}\text { Stinging, } \\
\text { swelling, } \\
\text { changes }\end{array} & \text { pigmentary } \\
\end{array}$ & $5(11.9 \%)$ \\
\hline $\begin{array}{c}\text { Group B surgical } \\
n=42\end{array}$ & $24(57.1 \%)$ & $\begin{array}{l}\text { Secondary infection, } \\
\text { scarring }\end{array}$ & $23(54.7 \%)$ \\
\hline
\end{tabular}

Table 2:- The frequency of recurrence rate after surgical removal and topical application in the treatment of MC.

\begin{tabular}{|l|c|c|}
\hline Time of follow up & RR after surgical removal & RR after topical application \\
\hline $2^{\text {nd }}$ month & $12[28.5 \%]$ & 0 \\
\hline $4^{\text {th }}$ month & $7[16.6 \%]$ & $5[11.9 \%]$ \\
\hline $6^{\text {th }}$ month & $4[9.5 \%]$ & 0 \\
\hline
\end{tabular}

Table-3:- The frequency of adverse reactions via the type of treatment in this study.

\begin{tabular}{|l|c|c|}
\hline Frequency of adverse reactions & Topical application & Surgical removal \\
\hline Stinging & $54 \%$ & 0 \\
\hline Redness & $65 \%$ & 0 \\
\hline Swelling & $16 \%$ & $33 \%$ \\
\hline Secondary infection & 0 & $26 \%$ \\
\hline Scarring & 0 & $14 \%$ \\
\hline Pigmentary changes & $38 \%$ & $26 \%$ \\
\hline
\end{tabular}

\section{Discussion:-}

Pediatric molluscum contagiosum virus (MCV) is a typical pox viridian infection that represents a standard public health issue. The spread of the virus among children is rapid and easy. The virus produces some substances that block immune response formation in the infected host. (4) Treatment options include destruction, topical therapy, and oral therapy. Destructive treatment modalities include curettage, cryotherapy, expression or pricking with a sterile needle, electrodesiccation, photodynamic therapy, and laser ablation. Destructive therapy is poorly tolerated in children, in addition to, it may cause pain and may leave scar behind. Topical medical treatment includes salicylic acid, glycolic acid, tretinoin, tazarotene, 5 percent sodium nitrite co-applied daily with 5 percent salicylic acid topical preparations, podofilox, liquefied phenol, tretinoin, cantharidin, and potassium hydroxide. (5) Trichloroacetic acid is a safe and effective agent frequently utilized in dermatologic practice, most commonly in the treatment of verrucae. (6) Patients with weakened immune systems have increased the difficulty in clearing lesions; therefore lesions typically persist for prolonged periods. (7)

In this study, we divided the patients into two groups concerning the number, size, and location of the lesions, and we selected surgical removal for those with a limited number of lesions $<5$, and whom their lesions were located in areas where TCAA is difficult to apply e.g. eyelids and lips. Patients with giant MC also selected for the surgical way to avoid the adverse effects of chemical application, and to ensure rapid clearance. Patients who have $>5$ lesions were treated by topical TCAA because they cannot tolerate the surgical treatment especially younger children. The common goal of most treatment methods is the destruction of lesions and the development of a localized inflammatory reaction.(8) Molluscum is a self-limited viral infection, and an inflammatory phenomenon often precedes disease resolution.(9) We noted that redness, local swelling and stinging were more noticeable with topical TCAA, while the risk of infection is more with surgical group. The time needed for complete clearance of the lesions was longer in surgical group than in the topical group. Patients with surgical group showed high recurrence rate with two to five visits every 2-3 months during follow up period, as the chance for autoinoculation is more pronounce in peoples who exposed to trauma ( Koebner and pseudo-Koebner phenomena) (10) especially if they have suppressed immunity. Many patients in this study mentioned a history of atopy and atopic dermatitis. And this will add a further risk of reinfection and autoinoculation, due to associated scratching. The loss of skin barrier function in atopic dermatitis and alteration in cell immunity make the stratum corneum susceptible to microbial colonization, (11-13) so we preferred to treat $\mathrm{MC}$ in atopic patients by topical TCAA to avoid recurrence. Recurrences of molluscum contagiosum are common, and realistic expectations regarding the potential for treatment failure and recurrence should be discussed with the child and his or her family prior to initiating any therapy.(14) We have to consider the location, extent of the lesions, the socioeconomic level of the parents and ability of the children to tolerate the type of treatment suggested before we started to treat them. 


\section{Conclusions:-}

In this study, topical application of TCAA $30 \%$ proved to be more effective than surgical removal in treatment of MC, with the further benefit of being more safe and tolerable and of low-cost to the patients The recurrence rate is significantly less with topical treatment than with surgical removal of MC. Topical treatment should be considered as a preferable modality in treatment of MC.

\section{Acknowledgments:-}

The authors would like to thank Mr. Abbas AL-Naeli, medical assistant, for his contribution in documenting patient's records.

Figure 1:- $\mathrm{MC}<5$ in number treated by surgical removal

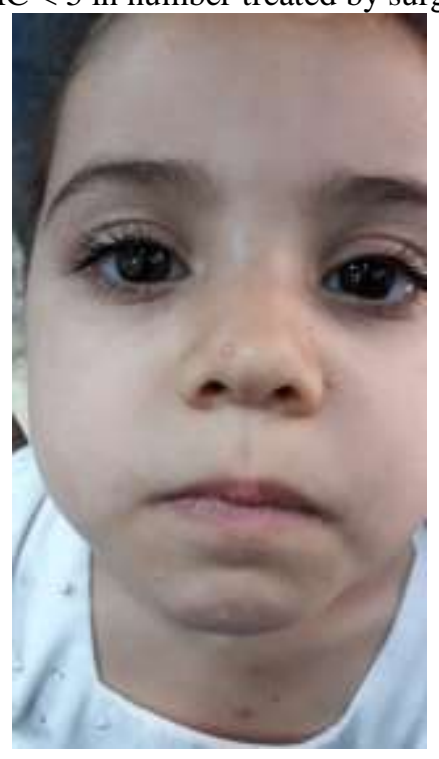

Figure 2:- MC > 5 in number treated by topical TCAA $30 \%$.

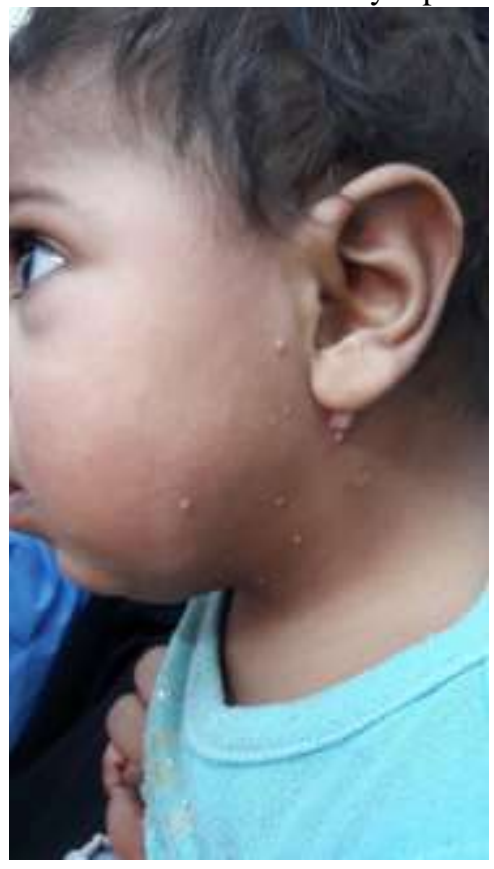


Conflict of interest:- None declared

Funding:- No funding source

Abbreviations:- TCAA ; Trichloroacetic acid , MC ; molluscum contagiosum

\section{References:-}

1. Klaus Wolf, Lowell A, Goldsmith, et al.; Fitzpatrick's dermatology in general medicine; $7^{\text {th }}$ Ed. 2008 ; 195 , 1909

2. King K. Holmes, P. Fredrick, et al.; sexually transmitted disease $4^{\text {th }}$ Ed. 2008; 30; 545-550

3. Howard B Pride, Albert C Yan et al. ; Pediatric dermatology 2008 MC 64-65

4. Silverberg N, Pediatric molluscum contagiosum: optimal treatment strategies; Paediatr Drugs. 2003;5(8):505-12.[ PubMed]

5. Scheinfeld N, Treatment of molluscum contagiosum: a brief review and discussion of a case successfully treated with adapalene. Dermatol Online J. 2007 Jul 13;13(3):15.

6. Bard S, Shiman MI, et al., Treatment of facial molluscum contagiosum with trichloroacetic acid. Pediatr Dermatol. 2009 Jul-Aug;26(4):425-6

7. Tyring SK, Molluscum contagiosum: the importance of early diagnosis and treatment. Am J Obstet Gynecol. 2003 Sep;189(3 Suppl): S12-6 [PubMed]

8. van der Wouden JC, van der Sande R, van Suijlekom-Smit LW, Berger M, Butler C, Koning S. Interventions for cutaneous molluscum contagiosum. Cochrane Database Syst Rev. 2009 Oct 7. CD004767. [Medline].

9. Mancini A, Viral infections. In: Schachner LA, Hansen RC, Eds. Pediatric Dermatology. 4th Ed. New York, NY: Churchill Livingstone; 2011:1466-1469

10. Devinder Mohan Thappa, The isomorphic phenomenon of Koebner; Indian journal Dermatology Venereology Leprology, Year: 2004 | Volume: 70 | Issue : 3 | Page: 187-189

11. Seize $\mathrm{MB}^{1}$, Sanchez M, Cestari Sda C., A study of the correlation between molluscum contagiosum and atopic dermatitis in children. A Bras Dermatol. 2011 Jul-Aug;86(4):663-8.[ PubMed]

12. Alexander K. C. Leung, Benjamin Barankin; MOLLUSCUM CONTAGIOSUM AND ATOPIC DERMATITIS. Consultant: Volume 14 - Issue 5 - May 2015 [PubMed]

13. Leung AKC, Hon KLE. Atopic Dermatitis: A Review for the Primary Care Physician. New York, NY: Nova Science Publishers; 2012:1-113

14. Smolinski KN, Yan AC.; How and when to treat molluscum contagiosum and warts in children. Pediatr Ann. 2005 Mar;34(3):211-21. [ PubMed ]. 